\title{
BRÁS, MOÓCA E BELENZINHO - "bairros italianos" na \\ São Paulo além-Tamanduateí
}

\author{
Margarida Maria de Andrade
}

No período que se estende, grosso modo, de 1870 até os anos 40 deste século, o Brás (incluindo parte do Pari), a Moóca e o Belenzinho transformaram-se de subúrbios de chácaras em bairros industriais e operários; a maior concentração de imigrantes e de fábricas da cidade de São Paulo, da última década do século passado atê as primeiras do atual.

Hoje, esses bairros são fortemente marcados pela presença de migrantes (nordestinos principalmente). A indústria que esteve na base de sua formação declina rapidamente. Mas, nem por isso perderam totalmente os traços de sua antiga identidade como "bairros italianos"; nem por isso a indústria desapareceu, embora os setores dominantes hoje sejam outros.

A reconstituição histórica de alguns aspectos da formação desses bairros, necessária à compreensão da sua realidade atual, fez emergir como um dos temas centrais o da Grande Imigração, promovida pelo governo brasileiro, no quadro de substituição do trabalho escravo pelo trabalho livre, visando "introduzir em proporçäo muito elevada imigrantes para a lavoura e em proporção diminuta os de outras profissões" 1

A análise de documentos sobre a Hospedaria de Imigrantes e de dados sobre a nascente indústria paulistana, revelou o impacto da política de imigração sobre a cidade de São Paulo, impacto esse que, ao que tudo indica, superou as previsões de seus formuladores, ou pelo menos daquela parcela comprometida com os interesses exclusivistas da cafeicultura.

Brás, Moóca e Belenzinho incluíam-se entre os novos bairros que nasciam em São Paulo pela concentração do contingente crescente de imigrantes que afluía à cidade uma yez iniciada a Grande Imigração.

No final do século XIX, quando Sāo Paulo apenas despontava no cenário urbano brasileiro, não eram poucos esses bairros. Além dos três citados, inclúam-se o
Bom Retiro, a Barra Funda, a Água Branca, a Bela Vista, o Cambucí, além de ruas e porções de bairros centrais.

Mas nenhum destes bairros destacou-se como o conjunto formado pelo Brás, Moóca e Belenzinho. Destacou-se como maior concentração de imigrantes da cidade e destacou-se como núcleo de intensa vida própria a ponto de merecer a designação de "outra cidade", comumente atribuída ao conjunto nos anos 30 .

As terras baixas sobre as quais se ergueram esses bairros localizavam-se a leste da velha São Paulo colonial. Ao longo do século XIX, as terras além-Tamanduateí compunham o chamado cinturāo de chácaras que envolvia o modesto núcleo urbano de São Paulo. Entre essas terras e a cidade dos tempos coloniais interpunham-se o rio Tamanduateí e sua várzea, sujeita a inundações anuais pelo transbordamento do rio na época das chuvas.

O rio e sua várzea eram verdadeiros obstáculos entre a "cidade" e núcleo mais antigo e os bairros de imigrantes que se formavam para além do rio. Com o tempo, o rio foi canalizado (obra iniciada em 1893 e que se estendeu por longos anos) e a várzea, drenada, deu lugar a um grande parque (Parque D. Pedro II, inaugurado no início da década de 20 ).

(*) Trabalho apresentado no Seminário "Indagaçǒes sobre a presença italiana no Estado de Sảo Paulo", realizado na FFLCH-USP, em outubro de 1991. Baseia-se na tese de doutorado apresentada ao Departamento de Geografia da FFLCH-USP, sob o título "Bairros além-Tamanduateí: o imigrante e a fábrica no Brás, Moóca e Belenzinho", São Paulo, 1991 (mimeo).

(**) Professora do Departamento de Geografia da Faculdade de Filosofia, Letras e Ciências Humanas/USP.

(1) Dados para a história da Imigração e da Colonização em São Paulo. In: Boletim do Departamento Estadual do Trabalho, Secr. da Agr., Com. e Obras Públicas, ano V, n ${ }^{\circ} 19,2^{\circ}$ trimestre de 1916 , São Paulo, p. 181. 
A incorporação das terras além-Tamanduateí à cidade, inicia-se ao mesmo tempo que grandes transformações nela se desencadeiam. Isso por volta de 1870.

Essas transformaçōes expressavam-se no crescimento da população que decorria, em parte, do estabelecimento na capital de "grandes proprietários $e$ capitalistas da Província ${ }^{\prime \prime}{ }^{2}$, mas decorria principalmente da vinda de imigrantes estrangeiros. Expressavam-se ainda na redefinição das condiçōes materiais da cidade que, além da expansão física e do aumento do número de domicílios, incluía também uma série de inovações ferrovia, iluminação a gás, abastecimento de água, rede de esgotos, bondes...

Nos documentos oficiais, algumas palavras traduzem as inovaçōes em curso - "embelezamento", "saneamento", "melhoramentos materiais". $\mathrm{Na}$ verdade, essas palavras expressavam um projeto ainda vago das elites de modernizar a cidade, de equipá-la com certos serviços urbanos, a partir de modelos oriundos das naçōes dominantes no cenário mundial no final do século XIX, de onde vieram tecnologia e capital investido na implantação de diversos desses serviços.

Eurípides Simões de Paula, referindo-se às grandes mudanças na cidade a partir de 1870 , falou em "segunda fundação de São Paulo" ${ }^{3^{3}}$.

As transformações na cidade de São Paulo nas últimas décadas do século XIX, têm suas raízes em modificações profundas na sociedade brasileira que inicia o movimento pelo qual à base agrário-exportadora se agrega o componente urbano-industrial.

A inauguração, em 1867, da primeira ferrovia paulista (a antiga São Paulo Railway), ligando o porto de Santos à zona cafeeira, marca praticamente, o início da transformação das terras além - Tamanduateí, de domínio de chácaras em espaço propriamente urbano. Contornando a "cidade" à leste e ao norte, a ferrovia, implantada nos baixos terraços que delimitavam a várzea do Tamanduateí (a leste) e a várzea do Tietê (ao norte), torna-se um elemento fundamental na estruturação da cidade e seus arredores. ${ }^{4}$

No que diz respeito às terras além-Tamanduateí, a Estação do Brás, inaugurada já em 1867, foi um ponto a partir do qual a urbanização avançou para leste, ao mesmo tempo em que a ferrovia passava a constituir mais um obstáculo, mais um elemento de separação (junto com o rio e sua várzea) entre a "cidade" e os novos bairros de imigrantes.

Dez anos depois, uma segunda estação ferroviária vem impulsionar a urbanização - ficou no Brás a estação da antiga Estrada de Ferro do Norte que, em 1877, ligou São Paulo à cidade do Rio de Janeiro.

É preciso destacar o papel destas estações ferroviárias impulsionando a urbanização. Embora a grande maioria dos imigrantes tivesse como destino as fazendas de café, muitos estabeleceram-se na cidade (seja retornando das fazendas, seja optando diretamente pela cidade). A presença de duas estações ferroviárias no Brás foi responsável pelo estabelecimento de imigrantes nas suas imediaçōes, tanto imigrantes entrados pelo porto de Santos, como pelo porto do Rio de Janeiro. Além deles, migrantes originários do interior do Estado e, eventualmente, de outros pontos do país também aí se fixaram (ex-escravos, brancos pobres).

Mas, um impulso muito mais poderoso à urbanizaçäo das terras além-Tamanduateí decorreu da localização no Brás da Nova Hospedaria de Imigrantes, inaugurada em 1887.

A primeira hospedaria data de 1881 e ficava no Bom Retiro. A exiguidade das instalações face à intensificação do fluxo imigratório no quadro da imigração subvencionada, levou o governo do Estado a construir a nova hospedaria, com capacidade para cerca de 4000 imigrantes.

As estações ferroviárias existentes no Brás foram determinantes na escolha do local, mas sozinhas não a explicam. Tanto é que o terreno que tinha sido comprado no bairro da Luz para aí ser construída a nova hos-

(2) Relatório do Presidente da Província Joāo Theodoro Xavier à Ass. Legislativa Provincial, de 05/02/1873, São Paulo, Typographia Americana, 1873.

(3) PAULA E.S. de, A segunda fundaçâo de Sảo Paulo (Da pequena cidade à grande metrópole de hoje). IN: Revista de História, $n^{\circ} 17$, jan-mar/1954, ano V, vol. VIII.

(4) Sobre o papel da ferrovia na estruturação da cidade e seus arredores, ver em especial LANGENBUCH, J. R., A estruturação da Grande Sáo Paulo - estudo de Geografia Urbana, Rio de Janeiro, IBGE, 1971. 
pedaria, localizado nas imediações das estações da Luz e Sorocabana, acabou recebendo outra destinação porque, nas palavras de um Presidente da Província, não foi julgado "próprio para um alojamento de imigrantes $o$ bairro (da Luz) que mais se presta a ser aformoseado, $e$ que vai merecendo a preferência da população abastada para ai construir prédios vastos e elegantes ${ }^{\prime 5}$. Assim, a escolha do Brás respondia também à estratégia da elite de segregar os imigrantes, de afastá-los dos bairros ditos burgueses.

O impulso à urbanização das terras além-Tamanduateí decorrente da presença da Hospedaria e o caráter segregativo dessa urbanização foram ressaltados por um parlamentar em 1895, ao declarar que

"O edifício da imigração, construído quando São Paulo era por assim dizer a metade do que é hoje, pelo próprio fim a que se destina, fez surgir em derredor a maior acumulaçäo de habitações destinadas a pessoas de baixa classe ${ }^{116}$

Para se ter uma idéia dessa acumulação, a população do Brás quintuplicou entre 1886 e 1893 (de 6 mil para 32 mil habitantes) e a população da cidade multiplicou por seis entre 1886 e 1900, ano em que cerca de $55 \%$ da população da cidade (que atingia $240 \mathrm{mil}$ habitantes), era formada de estrangeiros, em sua grande maioria italianos.

O exame de documentos sobre a Hospedaria de Imigrantes mostrou o impacto da política de imigração sobre a cidade de São Paulo e mostrou também, duas posições em confronto dividindo a elite - de um lado os que defendiam os interesses exclusivistas dos cafeicultores e, de outro (entre eles líderes na formulação da política de imigração subvencionada), os que defendiam a fixação direta nas cidades de imigrantes vindos no regime de subvenção.

Essa posição foi, por exemplo, defendida por Martinho Prado Jr. na Assembléia Legislativa em 1884. Este parlamentar considera como "limitação odiosa" a concessão de auxilio somente para os imigrantes destinados à lavoura, não existindo, na província de São Paulo exclusivamente lavradores ${ }^{7}$.

É inquestionável que a grande maioria dos imigrantes que se estabelecia na cidade retornava da gran- de lavoura, seja nos momentos de crise da cafeicultura, seja fugindo às duras condiçōes de trabalho nas fazendas de café. Entre esses, muitos abandonaram o Brasil. Mas, uma parte dos que se estabeleciam na cidade o faziam diretamente. Embora não seja possível quantificar, tudo indica ter sido significativo o seu número. Entre eles incluíam-se tanto imigrantes vindos com recursos próprios, como imigrantes vindos com passagem paga pelo governo brasileiro. Para muitos destes últimos, a opção pela cidade implicou na burla às normas do serviço de imigração que estipulavam o desembarque na Estação do Brás, junto à Hospedaria onde deveriam ser firmados os contratos de trabalho.

Em 1895, um deputado acusa que dos 74.975 imigrantes chegados em 1893, 37.641 não foram para a lavoura e 5800 não deram entrada na Hospedaria e teriam se espalhado em São Paulo, Santos, ou nas estaçōes intermediárias entre São Paulo e Santos ${ }^{8}$.

Nos documentos consultados, é nos meados dos anos 90 que a oposição de parcela da elite à fixação de imigrantes na cidade se manifesta de forma mais contundente. A concentração de estrangeiros na cidade já é um fato e passa a ser vista como ameaça.

Ameaça à saúde pública, na perspectiva dos parlamentares que decidiram em 1895 pela remoção da hospedaria para fora da cidade em seguida a um surto de cólera vitimando imigrantes recém-chegados. A grande concentração de imigrantes que se formara em torno da Hospedaria do Brás, na visão dos parlamentares, punha em risco a população da cidade no seu todo e punha em risco a continuidade do fluxo imigratório, vital para a economia cafeeira ${ }^{9}$.

(5) Relatório do presidente da Província Joăo Alfredo C. de Oliveira à Assembléia Legislativa Provincial - 1886, Săo Paulo, Typografia de Jorge Seckler \& Cia.

(6) Câmara dos Deputados do Estado de São Paulo, 78a Sessão Ordinária, 12/08/1895, Deputado Álvaro đe Carvalho, Projeto n 68 , em primeira discussăo.

(7) Cf. Discurso de Martinho Prado Jr. à Assembléia Provincial de São Paulo, Sessão de 1884, 14/02/1884.

(8) Cf. Câmara dos Deputados do Estado de São Paulo, Annaes da Sessão Ordinária de 1895, 78a Sessão Ordinária, 12/08/1895, Deputado Paula Novaes, Projeto no 68 , em primeira discussăo.

(9) Câmara dos Deputados do Estado de São Paulo, Annaes da Sessão Ordinária de 1895, 78a e 80a sessões ordinárias, deputađos Álvaro de Carvalho, Paula Novaes e Almeida Vergueiro. 
Indo mais longe na manifestação do antagonismo da elite face ao imigrante, um grupo de parlamentares, vendo na concentração de imigrantes na cidade uma ameaça à ordem pública, propõe a descentralização do serviço da Hospedaria de Imigrantes com a instalaçāo de hospedarias em pontos diferentes do Estado, de modo a garantir o estabelecimento dos imigrantes nas fazendas e impedir sua fixação nas cidades. Tal proposta foi derrotada ${ }^{10}$.

$\mathrm{O}$ antagonismo de classe subjacente à estratégia da elite de segregar os imigrantes, de afastá-los dos bairros da elite, acirra-se no final do século, diante do vulto que tomara a presença imigrante na cidade de São Paulo. Como desdobramento da política de imigraçăo que visava antes de tudo promover a entrada de braços para a lavoura, São Paulo tornou-se uma "cidade estrangeira". Ao mesmo tempo que em alguns bairros efetivava-se o projeto das elites de "embelezamento" da cidade, do outro lado do Tamanduateí, entre outras porçōes da cidade, multiplicavam-se os cortiços, havia falta de água e de esgotos, as ruas eram escuras e enlameadas, o lixo acumulava-se na Várzea do Carmo...

Os documentos sobre a Hospedaria, assim como estudos que discutiram a preferência pela cidade manifestada por parcelas de imigrantes, justificam pensar que o mercado de trabalho urbano constituía-se numa certa medida, diretamente ligado à expansão de atividades urbanas (entre elas a indústria que nascia) e não somente a reboque da grande lavoura.

O material pesquisado sobre a instalação de fábricas na capital e na Província (depois Estado de São Paulo) a partir de 1870 revela que embora preterida diante dos enormes favorecimentos à cafeicultura, $a$ indústria encontrou as condições de sua germinação em São Paulo.

Por outro lado, o exame da localização de fábricas nascidas no final do século XIX e início do XX mostrou a concentração das fábricas em alguns bairros da capital, entre os quais se destacava o conjunto formado pelo Brás, Moóca e Belenzinho.

De que indústria se tratava? Indústrias produzindo bens de consumo, na sua quase totalidade - tecidos, certos produtos alimentares; bebidas; chapéus; móveis; artigos de vidro; produtos da metalurgia leve e, com o tempo, uma incipiente indústria mecânica.

As fábricas de tecidos, de cerveja, de calçados, os moinhos de trigo, tinham produçāo muito concentrada em algumas grandes empresas. Mas a criação de pequenas firmas de ramos diversos parece ter sido uma das características da industrialização até meados do século.

Então, havia grandes fábricas como pequenas oficinas. As grandes pouco numerosas, tornaram-se mar$\cos$ fixos a dominar a paisagem dos bairros. As pequenas, em número nunca conhecido, misturavam-se ao casario. Mas, exceto para pequenas porções dos bairros onde as fábricas se sucediam umas ao lado das outras (como na faixa imediatamente contígua à ferrovia), grandes fábricas, oficinas, vilas operárias e cortiços se alternavam definindo a paisagem típica dos bairros.

Tanto grandes empresas quanto pequenas firmas são fortemente marcadas pelas figuras de seus fundadores - "capitâes de indústrias", como donos de pequenas oficinas que prosperaram nessa fase de estabelecimento da indústria de bens de consumo em poder do capital local.

Nos limites da pesquisa realizada, cabe destacar o papel do imigrante na indústria.

Apesar do acesso difícil aos dados, foi possível reconstituir, $\mathrm{cm}$ alguns de seus aspectos, a história de grandes empresas industriais fundadas em São Paulo pelo reduzido número de imigrantes entrados com recursos aplicados no comércio e depois na indústria, empresas essas que tiveram papel importante na estruturação dos bairros estudados. Os casos examinados nessa pesquisa foram os de Matarazzo e Crespi.

O estudo de grandes empresas mostrou a inserção crescente de imigrantes e seus descendentes como assalariados na indústria. O crescimento da indústria justifica pensar que um número sempre maior de imigrantes integrava-se diretamente à indústria como assalariados, sem passar, assim, pela grande lavoura.

(10) Cámara dos Deputados do Estado de Sāo Paulo, Annaes da Sessăo Ordinária de 1895,78 a e 81 a sessões ordinárias, deputados Paula Novaes e Carlos Villalva. 
Muito mais difícil foi examinar a inserção de imigrantes como autônomos no artesanato e na produção industrial em pequena escala. Estabelecidas no que se convencionou chamar "oficinas de fundo de quintal", as pequenas indústrias fundadas por imigrantes e filhos de imigrantes proliferaram na cidade de São Paulo. Inúmeras delas tornaram-se, com o tempo, empresas importantes, seus fundadores passando a compor a nascente burguesia industrial. Dois casos foram estudados: duas fábricas de teares nascidas no início dos anos 20 (uma, fundada por filhos de imigrantes italianos chegados em 1904 - Andrighetti; outra, fundada por um imigrante português e seu irmão nascido no Brasil - Ribeiro).

Cabe aqui ressaltar que a ascensão econômica e social de parcela de imigrantes entrados como força de trabalho, pela via da instalação de pequenas oficinas que se tornaram fábricas depois, não deve obscurecer o fato que a grande massa de imigrantes e seus descendentes veio a constituir a força de trabalho da nascente indústria paulistana.

Apesar das lacunas nos dados, a pesquisa mostrou que, ao iniciar-se o século XX, o Brás, a Moóca e o Belenzinho já despontavam como maior concentração da incipiente indústria paulistana. Daí em diante, fábricas e oficinas se multiplicam, a indústria passando a ser o elemento fundamental da integração desses bairros à cidade. $\mathrm{E}$, como bairros operários, reafirma-se o conteúdo segregador da urbanização que já estava presente antes da chegada da indústria.

Embora não seja possível apreender a realidade desse conjunto de bairros, na sua complexidade, a partir de um estudo que privilegia a indústria, a pesquisa apontou para a importância que a indústria desempenhou na estruturação dos bairros do Brás, Moóca e Belenzinho.

O exame da indústria levou a enfatizar a unidade que marcava esse conjunto de bairros, ainda que sem desconsiderar as diversidades entre eles.

O processo de formação desses bairros, não se resume à concentração da população e da indústria, mas inclui a concentração do comércio e serviços, de escolas, atividades culturais diversas, de formas diversas de associações entre trabalhadores e de formas embrionárias do movimento sindical. Nesse processo, um núcleo complexo de vida social se constituiu polarizado pelo
Brás, a designação de "outra cidade" traduzindo a complexidade da realidade social que caracterizou esse conjunto de bairros operários paulistanos até meados do século atual. ${ }^{11}$

No âmbito desse trabalho, o nascimento dos bairros foi enfocado a partir da consideração da ferrovia, de peculiaridades que marcaram a implantação de alguns serviços urbanos, do papel da hospedaria na aglutinação de imigrantes, das primeiras manifestações da indústria. Assim, a partir de aspectos diversos, a incorporação das terras além-Támanduateí pôde ser enfocada.

Depois, apenas a indústria foi destacada. Alguns aspectos do desenvolvimento da indústria foram então considerados (crescimento da indústria de tecidos, a nascente produção interna de teares, a ascensão e declínio da indústria tradicional).

Destas análises resultou o entendimento de que o mesmo processo que integrava os bairros além-Tamanduateí à cidade de São Paulo, dissolvia, desestruturava a realidade dos bairros industriais e operários da primeira fase da industrialização. Como elementos dessa estruturação-desestruturação: o abandono dos bairros pelos imigrantes enriquecidos pelo progresso de suas oficinas; a ascensão e o declínio de empresas; a expulsão de moradores que, impossibilitados de pagar os aluguéis em alta procuravam os loteamentos desprovidos de infra-estrutura que se abriam nas franjas da cidade; o abandono dos bairros por moradores expulsos pelas fábricas que para se expandirem compravam imǿveis residenciais contíguos a elas.

Em outras palavras, ao examinar a indústria na escala micro dos bairros e até de empresas, revelou-se, como sentido mais amplo a posição de São Paulo como centro do desenvolvimento industrial brasileiro, induzindo o crescimento da cidade em um ritmo cada vez mais acelerado, próprio dos processos de metropolização. A cidade passa então a concentrar o fluxo migratório interno de trabalhadores expulsos do campo. Trabalhadores nacionais integram-se como mäo-deobra industrial.

(11) Os fundamentos para estudar o bairro considerando-se as características atuais do processo de urbanizaçăo, encontrei em LEFEBURE, Henri, Quartier et vie de quartier, IN: Du Rural à l'Urbain, Anthropos, Paris, 1970, p. 207-215. 
Os bairros além-Tamanduaté, polarizados pelo Brás, apareciam à elite paulistana da primeira metade do século como "uma outra cidade", "com outra gente $e$ outra vida", lugar de uma "população laboriosa"12.

\section{O que resta hoje desta "outra cidade"?}

Marcas na paisagem já muito alterada; lembranças de velhos moradores.

\section{RESUMO}

A formaçăo dos bairros do Brás, Moóca e Belenzinho vincula-se diretamente è política de imigração subvencionada pelo Estado no quadro da substituiçăo do trabalho escravo pelo trabalho livre. Tal política, que visava suprir, primordialmente, as necessidades da cafeicultura em força de trabalho, foi também responsável pelo estabelecimento de imigrantes na cidade, atraídos por atividades urbanas em expansão, inclusive por uma incipiente atividade industrial. $O$ exame mais detido dessa incipiente indústria que se instala em São Paulo a partir do final do século XIX, mostrou seu papel essencial na consolidação dos bairros do Brás, Moóca e Belenzinho, sobretudo nas primeiras décadas deste século. Ao mesmo tempo, a reconstrução da história de algumas enıpresas industriais revelou, no processo de crescimento da indústria, elementos indicativos da dissolução dos velhos bairros industriais e operários, os denominados "bairros italianos".

(12) "O Estadinho", 27/01/1919. Citado por ARTIGAS, R. C. e BAYEUX, G., Brás - espaço e uso. In: Casa das Retortas, IDART Departamento de Informação e Documentaçāo Artísticas, Secr. Municipal de Cultura, Prefeitura do Município de São Paulo. 